\title{
The Importance of Movement for the Overall Development of the Child at Pre-School Age
}

\author{
George F. Zarotis
}

Lecturer, Faculty for Human Sciences, University of the Aegean, Rhodes, Greece

DOI: $10.36348 /$ jaspe.2020.v03i02.003 $\quad$ | Received: 01.02 .2020 | Accepted: 12.02 .2020 | Published: 16.02 .2020

*Corresponding author: Dr. George F. Zarotis

Abstract

The lack of exercise in childhood is caused by a variety of different factors. In order to illustrate the consequences of a lack of exercise, the effects of exercise on child development will be discussed. The aim of the present study was to identify the multifunctional importance of movement in all areas of child development on the basis of various research studies. The method used in this study was a review of the relevant literature. By analysing various research results, we discovered that due to the increase in postural weaknesses, postural defects and motor deficits in children and adolescents and the associated cognitive consequences, various studies and publications have been conducted in recent years, in which effective physical education at pre-school age is repeatedly mentioned as the cornerstone for the holistic development of children. Movement activities and physical activity can have a positive influence on physical development in the following areas: a) improved development and increased performance of the cardiovascular system, b) age-appropriate development of the muscular system, c) high resilience of the skeleton and d) positive contribution to the formation of a correct posture and avoidance of postural weaknesses and postural damage. Numerous scientific studies have shown that there is a connection between movement activity and intelligence development. For example, children of pre-school age achieved better results in intelligence tests than the non-subsidised control groups through regular physical activity promotion. In addition, targeted motoric promotion has a lasting effect on improving concentration. Particularly in early childhood, versatile physical activity can have a positive influence on the development and training of mental abilities. In childhood, movement activities have a high experience value. Victory and defeat, joy and sorrow, happiness and disappointments - sport and play provoke a variety of emotional states that have a lasting effect on the emotional development of children. Through movement, the child tests its body. It learns to deal with it, to assess it and it feels the limits of its own body. Due to their physical activity, children experience recognition from their peers and adults. Such experiences are of great importance for the development of self-confidence and mental balance. Since a large number of physical activities in childhood are connected with group activities, there are various social educational effects for the growing person. Movement, sport and play can provide important impulses and helpful lessons for personal adaptation, interpersonal relationships and appropriate social behaviour. In summary, it can be said that exercise has effects on the whole person. Different areas are addressed by exercise and can therefore be promoted through exercise.

Keywords: Pre-School age, motor, cognitive and psychosocial development of the child.

Copyright @ 2020: This is an open-access article distributed under the terms of the Creative Commons Attribution license which permits unrestricted use, distribution, and reproduction in any medium for non-commercial use (NonCommercial, or CC-BY-NC) provided the original author and source are credited.

\section{INTRODUCTION}

Nowadays, children's everyday life is increasingly characterised by a lack of exercise. Problems can arise in motor, cognitive, emotional and psychosocial development. In addition to genetic determination and malnutrition, inactivity is now considered a major causative factor. Furthermore, lack of exercise during childhood leads to a disturbed overall development of the child. The importance of movement for the child's development recedes more and more into the background. Changes in living conditions, increasing motorisation and a lack of opportunities for play and movement, which are involved, among other things, in the development of passive leisure activities for children, support this trend. This study is intended to illustrate that the best developmental support for children can be achieved through exercise. Exercise not only supports motoric development but also cognitive development, as it enables different experiences that the child has to process. Movement can also have a positive influence on the development of the personality. 
Furthermore, movement has also a positive influence on structural brain development and information processing [1]. Since children have a strong urge to move and are not yet able to put off their needs, concentrated learning can probably be best achieved in motion or at least with breaks for movement. Various studies have already shown that exercise causes increased brain circulation and thus increases attention [2].

Exercise accompanies people throughout their entire lives. The first movements already take place from the third month onwards in the form of prenatal movements in the womb. The last movements end with death. The concept of movement is very comprehensive and does not always refer to sport or locomotion. Nor does the importance of movement have the same priority in the different age groups. Most important is the movement in childhood. This is reflected in the enormous need for movement in children. Movement and play are sometimes the most important elements in child development and serve to explore and understand the own body and the environment. Experiences gained through independent activity in movement and play lead to a gradual development of the child. The child is guided by an inner urge to develop and to constantly improve its skills. A movement-friendly environment supports this process, whereas poor external conditions reduce or regress this natural urge to move with corresponding effects on the overall development. In addition to the negative effects on health and wellbeing, low movement stimuli also impair the motor, cognitive, psychological and social development of children. The reason for this is that movement never occurs alone, but always in conjunction with psychological processes [3]. Terms such as sensomotorics and psychomotorics illustrate this connection between movement, action and perception. For example, arbitrary movement is not possible without perception. Due to the depicted complexity in terms of the multiple entanglements and effects on human development, movement can be replaced by nothing. Neither through technological progress nor through medication. Thus, already in elementary education it represents a decisive pillar in development. In early childhood, which is a decisive stage in the socialization of a person, a basic attitude towards movement is formed. So that movement is later seen as normality and not as an exception, movement activities must already be part of everyday life here. By adopting a perspective that views movement as normal everyday activity, it is possible to achieve far-reaching and longterm health-promoting effects [4]. The observed demographic changes in society have a strong impact on the socialization and number of children. The sharp decline in the birth rate in recent years has a restrictive effect on children. The streets and squares of the residential environment are becoming increasingly childless due to the low number of children. As a result, the neighbourhood playgroup necessary for spontaneous play is no longer available, and single children are left alone in their environment in addition to being alone in their homes. The decrease in the number of children leads to a decrease in the movement of the individual children. The main reason for the decline in the birth rate is the increased educational opportunities for women and the associated increase in employment. These developments led to changes in family composition. The normal family lost its monopoly status and one-child families or single-parent families are increasing. Single parents have to cope with problems such as limited material resources and time constraints in childcare due to their additional burden. As a result, the restrictive effects on the mobility of children growing up in such a family form are greater. Opportunities for play and the restructuring of the living environment have decreased significantly. The street, as the most popular place for children to stay, plays a key role here. Due to the increasing traffic on the streets, there is almost no possibility for children to use them as a play area for a while. In addition, there are forms of settlement in which functionless places do not exist and children are only allowed space on playgrounds. In many cases, it is not possible for small children to visit them alone, so they are dependent on the help of older people. Due to the changed living environment, children retreat into indoor spaces and thus limit their movement activities [5]. Television, computers and toys also have an impact on the physical activity of children. Television is the most common leisure activity of families. Children have the opportunity to choose from a variety of programmes and select the one that interests them most. With a computer, they can also make decisions within the programme. There is interaction between the computer and the child, but physical activity is also very limited. Modified toys, as advertised by the various manufacturers, allow children to have fun even when playing alone indoors. The prefabricated toys have become more technical and have defined functions. Due to the large amount of toys, children no longer have to improvise and make their own toys from everyday objects and natural materials. This has changed not only the toys but also the way they play. As a result of the changes in space, the family and the toy equipment shown here, children's movement is significantly restricted. In addition to the health consequences, these changes have a multitude of other effects on the development of children, which illustrates the necessity of a special consideration of movement offers in elementary education.

The positive effect of sports and physical activity on children's development has been proven. In addition to the importance of physical activity for the development of children of pre-school age, changes in the world of life and movement of children are undisputed [6]. 


\section{METHODOLOGY}

The present study is a bibliographical survey study that presents the critical points of existing knowledge about a theoretical approach to the topic of "the importance of movement for the holistic development of pre-school children".

There is no specialized and comprehensive research in this area. This study attempts to fill this gap and may be a useful aid for those who will make similar efforts in the future. The main objective of the bibliographical review is to integrate the study into the "body" of the subject in question. The review of the current study refers to clearly formulated questions and uses systematic and explicit criteria for the critical analysis of a published paper by summarizing, sorting, grouping and comparing.

\section{BIBLIOGRAPHIC REVIEW STUDY Influence of Environmental Conditions on Child Development}

In addition to pollution and climate change, children are also affected by environmental factors such as road traffic and living and playing conditions. The development of children is to a considerable extent determined by the influences of the environment. The mere fact that more and more cars are registered every year makes the situation of child development more difficult. The increasing traffic density restricts the children's range of movement. Children often find it more difficult to find places and niches that they can appropriate for themselves. With the unplayability of the streets, the growing ups are literally forced into artificially created spaces such as playgrounds, green spaces etc. Childhood habitats are not only influenced by the development on the streets. In addition to the increase in road traffic, increasing building development and the limited preservation of natural open spaces lead to a restriction of the children's space for movement. As a direct consequence of this development, the habitat is becoming isolated. Living, work, consumption and leisure time are separated from each other and can usually only be reached via the traffic network. It is therefore almost impossible for children to pursue various leisure activities independently. Their leisure activities are largely dependent on their parents, - who have to act as taxis for the children. Everyday leisure time destinations can no longer be reached by bicycle. The child gets more and more into the situation to plan his carefree playing early. A further point that is characteristic for the development of children's living spaces is the domestication of children's play. Everyday life is increasingly shifted from the outside to the inside. The parental home is more and more regarded as a play and adventure area, the attractiveness of which depends strongly on the living conditions. The children are thus denied the experience of large-scale movement. A dealing with nature hardly ever takes place. The prestructured social spaces such as playgrounds and planned green spaces determine the children's space for movement. The leisure behaviour of the children is influenced above all by the modern forms of settlement, the unplayability of the streets and the attractiveness of technical play materials. The result of these changes is the increasing shift of playing in the home or children's room. The urge to move around can no longer be exercised on a large scale and more activities are carried out in a sitting position, which is illustrated by a $50 \%$ decline in the amount of movement in children's everyday lives [4]. When the child is active outside the protected space, he or she is immediately confronted with the dependence on the parents and scheduling issues. The free time of the children is mostly planned. Spontaneous activities or free play are hardly possible. The children's everyday life is determined by ballet lessons, music lessons and other forms of instruction. Another reason for the decline in playing in the open air is the unattractiveness of playgrounds. Due to the fixed structures, the playgrounds offer little room for change and childlike imagination. Thus, in most cases the children are left with only the possibility to do the same thing all the time. Much more interesting for the children are therefore the available toys within their own four walls. With elaborate colour designs and references to current TV series, the toys invite children to use and operate them. A free fantasy development is only given to a small extent. It is rather the enormous abundance of play materials that leads to a targeted stimulus satiation and thus arouses the interest of children. The curiosity for cheap toys and system toys is specifically trained by the media. The dominance of television and video in children's everyday lives is deliberately exploited to make these play materials attractive. The increasing TV consumption of as little as two hours a day among two-year-old children, in addition to rising sales figures in the toy industry, is leading to less exercise, fewer social contacts and a decline in children's direct experiences [7].

The physical activity behaviour of children is made up of the natural urge to move and the influence of the factors listed above (family, social status, street socialisation, nutrition etc.). The everyday life of today's children is characterised by a decrease in physical activity. Sedentary activities dominate the daily routine of today's society and thus affect the physical activity of children. To illustrate the movement behaviour of children, movement is divided into different categories. Physical activity is divided into: sports in clubs, sports in leisure time, sports in kindergarten or playing in school and outside [8]. In summary, it can be said that the changed conditions of growing up cannot only create new life opportunities for the majority of children, but they can also cause a variety of burdens at the same time. The demands on children have changed. On the one hand, children become independent earlier, make more use of the offers of institutional facilities and experience more emotional bonds from their parents than before. On the 
other hand, there is more social inequality, which can affect the children of single parents, migrants and families with many children. The provision of inactive leisure activities and the fact that many distances are covered by car can promote a less active childhood. The prefabricated toys and structured playgrounds do not offer children too many opportunities for creative motor activity. The question now arises as to whether the listed strains can be compensated for by the children's natural urge to move. It is also important to what extent the children's everyday life still offers free space in which sufficient stimuli are available to ensure motor development [9].

\section{Influence of Movement on Motor Development}

Motor development is a partial aspect of the child's holistic development and change process. It is influenced by several factors: biogenetic predisposition conditions, environmental and socialisation conditions, learning and self-control processes. The learning and self-control processes are in turn influenced by socialisation and environmental factors. Overall, there is an interaction between the above-mentioned factors. Motor skills and abilities are improved by the quantity and quality of the exercise. The exercise ensures the progress of development and the extent of the exercise depends on the inner attitude of the child and also on the personal and material environment. The environmental conditions and stimuli that have a movement-enhancing effect on a child have a high significance for the motor development of the preschool child. Children who find good conditions in the material environment show significantly better motor performance than children with less good conditions. The promotion of children's individual functional areas of the motor system is without doubt successful. Provided that pedagogical and training-scientific principles are observed and there are no serious pathological side-effects [10]. Children who were motor stimulated at an early age show better performance in later stages of development, especially in the areas of movement quality, movement accuracy, balance ability and reactivity. Motor deficits in pre-school children are a significant factor in accidents. This is not surprising. For it is obvious that a child who reacts more slowly, acts clumsily or is unsure of his or her balance, for example, has a higher risk of accidents. On the other hand, a child with good motor skills has more opportunities to avert an impending accident situation through his motor skills and abilities. However, it should not go unmentioned that good motor skills can also lead to overconfidence in children [11].

Adequate exercise promotes sensory development. Every conscious movement stimulate both the neuromuscular system and the central nervous system. This ensures the formation and protection of nerve cell structures. The development of perception and motor skills run parallel, since every incoming information leads to a motor reaction. In addition, perception and movement play a decisive role in the development of a positive self-concept. If the child has a disturbed self-perception, little material experience or social experience, this can lead to problems in the holistic development. Through increasing independent locomotion possibilities such as crawling and the first free walking, the range of experience in the environment increases significantly. In the first three years of life, children enjoy movement out of pure functional lust, so that they have a pronounced urge to move [12]. This leads to the acquisition of various forms of movement, the most important of which are: walking, climbing up, balancing, jumping down, running, hopping, jumping, crawling, rolling, pushing, pulling, climbing, hanging, swinging, carrying, the beginnings of catching and various forms of throwing.

Infants need sufficient space and freedom of movement for normal motor development. The main method of pedagogical guidance is based on the initially stimulating movement task, the movement-guiding, the securing help and the verbal encouragement of the children's trying and effort. It is important to use language support appropriate for the child, as this promotes contact, concentration, initiative and language development. On the basis of an increased repertoire of movements, pre-school children have achieved a capacity for action that gives them increasing autonomy and independence. Building on the previous developmental phase, the acquired forms of movement are qualitatively improved, made variably available and are they used in movement combinations. While combinations of movements were still extremely difficult in infancy, they are increasingly successful in pre-school age. For this reason, pre-school age is described as the phase of perfecting various forms of movement and acquiring initial combinations of movements. Such combinations are running up and down, throwing up and catching a ball again while walking, bouncing a ball while walking. In preschool children who receive an intensive athletic education, one can observe far above average movement combinations and forms. These trained preschool children can already master basic sports techniques. The motor skills of boys and girls increase equally, since the gender-specific differences in pre-school age are still slight. In contrast to small children, preschool children are less likely to be distracted. They approach the challenges and the tasks set to them in a more concentrated, serious and persistent manner, even if these tasks are associated with difficulties. The need for movement is even more pronounced in preschool children than in toddlers [13].

\section{Influence of movement on the development from the biological-medical point of view}

In the current medical literature on paediatrics, only brief references to the aspect "significance of exercise for physical, organic development" could be found. The structure, health and performance status of 
an organism are determined both by its genetic make-up and by the quality and quantity of its strain. The dynamic strain on large muscle groups provides an adequate stimulus for the development and maintenance of the performance of the internal organs, especially the heart, circulation, respiration and metabolism. This biological law applies especially to the child's organism, as it is still in full development and is dependent on necessary biological developmental stimuli. Sufficient exercise plays a decisive role in the development of a healthy, efficient active and passive musculoskeletal system. The natural urge to move ensures physical and motoric development, as movement provides the necessary stimulation. Children before puberty show a strong plasticity of the central nervous system, which is responsible for the high learning ability. With regard to brain development, the child must be offered sufficient stimuli for optimal networking of its nerve cell structures in the central nervous system, as otherwise the infraarchitectonics of the nerve cell assemblies will be of poorer quality or the functional maturation will be reduced. The movement represents such a stimulus [14]. According to Schack \& Pollmann [15] thinking and intelligence are important in the perfection of movement actions and this statement is also valid the other way round. For movement exercises have a positive effect on those cortex regions of the cerebrum in which the relevant mental processes take place. It is also pointed out that through reafference of a movement action, metabolic processes in the brain are activated and that optimal excitability is ensured in those brain areas where the responsibility for the highly complex control and regulation of movements lies. The decisive factor in pre-school age in order to keep as many nerve cells as possible alive is motor function. Motor function is an essential prerequisite for the optimal development of the cerebral cortex and the central nervous system. Through movement, the vegetative nervous system can be influenced favourably with regard to relaxation and calming.

\section{Influence of Movement on Cognitive Development}

Especially in the first two years, the mental development of children receives the necessary impulses through movement and perception. Perception refers to the taking in and processing of impressions with the help of sensory organs. Through versatile movement, the children actively experience their environment and the sensory organs receive the necessary and versatile stimuli for their development. Movement is therefore an important prerequisite for the development of the sensory organs. In humans, perception as a basic ability is present in average quality from birth, but in order to reach a higher level it must be practiced in childhood. Through varied practice of the sensory functions, movements become safer. For the interaction of the senses, movement activities have a supporting and promoting effect, as physical activity stimulates the sensory organs and triggers adaptation reactions. These impulses in turn enable the brain to optimize processing and to continue to develop [16]. Such adaptation processes are accommodation and assimilation. In assimilation, the child tries to integrate new environmental influences and experiences into existing structures which are based on past experiences. If new experiences and influences cannot be processed with the help of the existing structures, the structures must be changed. This adaptation of behaviour patterns to the environment is described as accommodation. Accommodation and assimilation influence each other, because an adaptation mechanism triggered by accommodation is added to the behaviour patterns after its consolidation and is consequently used in the sense of assimilation. Intelligence is the highest and most variable adaptation of the individual to his environment. With the quest for independence, adaptation is understood as an active process. Perception and movement are very closely connected, which is evident in the fact that arbitrary movement is only possible through perception. This connection is described by the term "sensomotorics". Accordingly, sensorimotor intelligence is an intelligence that is based exclusively on movement and perception, but not on imagination and thinking. With the increasing development of cognitive abilities, it loses influence, but in certain situations sensorimotor intelligence still plays a role in adults. Since thinking initially takes place in the form of active action, action-bound material experiences have an outstanding function in the development of sensorimotor intelligence. Material experiences form the basis of cognitive development [17]. During movements, children always learn about the characteristics of the objects they are handling. The concepts of grasping and understanding are not only related linguistically. Material experiences are gained through practical involvement and experimentation with the environment, which leads to theoretical experiences. When children swing, for example, they gain knowledge about the principle of rocking. By changing their position on the floor and through different postures, they learn about physical attributes. Movement activities are thus necessary requirements for gaining material experiences, but they are not themselves the subject of these experiences. Empirical studies have shown this connection between motor and cognitive development. Children with good motor skills scored better on intelligence tests. An additional offer of movement led to better results in the intelligence tests compared to a control group. Throughout the entire developmental process, the promotion of intelligence through physical activity always occurs only within the limits of genetic preconditions [18]. Language development takes place very rapidly at preschool age. "Language" cannot be equated with "speaking", as speaking is a special form of language. The term language refers to the different forms of body language and speech. Speaking is learned by speaking, but the prerequisites for speaking can be created by a versatile movement and perception development. Movement games therefore also have positive effects 
on the linguistic development of children. The close connection between movement and cognitive abilities described above makes the separation of body, mind and soul seem pointless. Despite the above mentioned findings, the school and educational system is oriented towards Cartesian thinking, which strongly emphasizes the separation of body and mind [19].

\section{Influence of Movement on the Development from the Psychological Point of View}

Body and movement experiences are an important component in the development of the child's self-concept. The self-concept is the image that a child makes of itself. The self-concept shapes the child's assessment, expectations and attitudes towards itself. Through physical activity, children learn about possibilities and limits in relation to themselves and their environment, they discover their effectiveness and directly feel success or failure [20]. The self-concept is based on the one hand on the cognitively oriented selfimage and on the other hand on the more emotionally oriented self-esteem. Thus, the self-concept consists of two pillars: The first pillar consists of own interpretations based on self-experience; the second pillar consists of external interpretations about oneself. How the child perceives itself based on its self-concept has a decisive influence on its behaviour. The subjective assessment of abilities does not necessarily have to correspond to the actual abilities. Since movement-oriented skills are highly regarded by children, motor failure experiences very quickly have a negative effect on self-concept. A negative self-concept can only be changed if the success of an activity is perceived as such and is not interpreted as a coincidence or an externally determined influence. Children must therefore be given the opportunity to become active themselves in order to break the vicious circle. Appropriate offers of movement are particularly suitable for this purpose, as they are already for the development of a positive self-concept [21]. Movement and self-activity play a decisive role in the formation of personality. Attitudes acquired in early childhood are very stable and resistant to change, which gives the formation of a positive self-concept a further important meaning. If the movement experiences and memories from childhood are positive, the chances that movement activities are maintained over the entire life span, possibly in the form of a movement-oriented lifestyle, increase accordingly [22]. With movement experiences, the child always has sensory experiences as well; sensory and perception are complex psycho-physical events. Children perceive sensory impressions with the whole body, emotional expressions take place in movement and joyful experiences of movement lead to physical and psychological relaxation. In addition, children can develop their creativity in movement, which in turn has an important meaning for cognitive development. Movement helps the children to release pent-up energies, frustrations and fears. Movement gives the children a zest for life and fun. With an increase in motor skills, self-confidence increases at the same time [23]. The child gains self-confidence and self-esteem through movement safety. With increasing confidence in movement, the child's urge for autonomy and independence increases. This is increasingly reflected in the desire to master activities such as eating or getting dressed without outside help [24].

\section{Influence of Movement on Social Development}

The development of society is characterized by a rising standard of living and an increase in the prosperity of the population. The considerably increased standard of living among broad sections of the population and a still well-functioning social safety net mean that a large proportion of children today grow up in a world of experience and consumption largely freed from existential problems. This trend has continued to this day, but it should not hide the fact that despite an increased net income, a better level of education and a rise in living standards, inequality and poverty in society are occurring.

The family is probably the most important framework for child development. Norms, commandments, prohibitions and health- or diseaserelated behaviour of children and adolescents are mainly conveyed by the family. Changes in the family form, in the parent-child relationship and in the distribution of roles within the family bring about a constantly changing constellation. It becomes clear that the demands on the family and the traditions within the family have changed considerably over the last decades. Thus, the traditional image of the extended family is disintegrating more and more into the most diverse family forms. Although this creates more freedom in the design of the child's own living space and more individuality, - a certain degree of social security, reliability and stability is also lost [25]. In addition to changes in the family form and the distribution of roles, the significance of children for their parents is also undergoing a certain change. Children no longer serve merely to provide for their parents' retirement, to continue the family tradition or to pass on the family name. They rather give them a new meaning in life. The concentration on only one child increases the uniqueness and meaningful function of the offspring. From this change of meaning a new way of dealing with children develops. On the one hand, the parents' control grows out of fear that something might happen, and on the other hand, the expectations regarding the children's learning success increase. The overprotection of the child shows the special position in the family. The parents are supported by an abundance of educational guidebooks, but at the same time they are made insecure [26]. The increasing pedagogy is expressed in books, courses or even television series, in which parents are given tips but above all they are made to feel unable or overtaxed in the education of their child. This recourse to external advice is due to the fact that parents have less time and energy for the education of 
their children. Regardless of being married or single parents, they are usually so heavily burdened in their own way of life that the children come off badly. The pressure in the professional world, the fear of losing one's job and the insecurity in existential care are factors that can put a strain on the parent-child relationship [27]. Parents with a low socio-economic status are passive in their leisure activities with their children. The parents' sense of duty decreases. The responsibility of parents to care for their children decreases with the age of the child. In childhood, the foundations for the acquisition of social behaviour are laid. Since many pre-school physical activities are connected with group activities, the child has to discuss and agree on common game ideas and rules with other children. This inevitably has an influence on social behaviour. In this way, basic linguistic communication skills are also acquired [28]. The motor skills of a child can be decisive in determining whether a child is accepted by other children as a play partner or not. This aspect is also important for the child's self-esteem. Motor retardation leads to social isolation, which in turn inhibits motor development. In the development of basic social skills, which takes place in early childhood, movement games play an influential role. With the help of movement activities, social experiences can be gained and tested, because the development of social competence does not take place through educational measures by third parties, but on the basis of experiences with others. Children are more willing to learn from other children than from adults. Therefore, children need children in order to grow into a social community. In mixed-age groups, younger children can adopt the movement and behaviour patterns of their elders by observing them, and at the same time older children have the chance to escape the competitive pressure of their peers. In order to take into account the individual interests of the different age groups, there are also heterogeneous and sometimes homogeneous group divisions to be considered. Exercise offers and games are very suitable to promote the ability to cooperate, tolerance behaviour, rule acceptance and increased frustration tolerance in case of failure [29]. Physical performance is an important means for children to gain recognition in the group. Children with good motor skills are regarded as equal play partners and are generally more popular than children with poor motor skills. Children with motor skills that are not so well developed sometimes can have negative experiences through movement games. In order to avoid further negative experiences, the affected children withdraw from movement activities. In addition to the exercise time and the associated increase in motor performance differences, a withdrawal also reduces the possibility of experiencing social contacts [30]. In addition to the positive influence of movement on social experience, it can also be a limiting factor for children's opportunities for contact. It is therefore necessary to enable all children to develop their personal limits and individual motor skills through a variety of movement activities [31].

\section{CONCLUSIONS}

Lack of exercise leads to a disturbed overall development of the child in childhood. Problems in motor, cognitive, emotional and psychosocial development can occur. People involved in the upbringing and care of pre-school children must train the children's awareness and responsibility for their own bodies. Parents and educators should act as role models conveying the fun and enjoyment of daily exercise and healthy nutrition. Institutional facilities such as kindergartens or other day care facilities have a special importance in the health education of children. The lack of understanding of some adults for an active life and healthy nutrition, as well as the inadequate design of children's exercise areas by cities and municipalities must be compensated for by the introduction of exercise programmes. These physical activity programmes would reach the majority of children at an age when the development of individual risk factors could still be effectively prevented. It is therefore useful to introduce primary preventive measures to promote physical activity as early as possible. Through physical activity promotion, children can gain self-awareness, sensory experience, experience of the world, experience of expression and creativity, which they need for the development of a positive self-concept in the sense of salutogenesis [32]. Due to the increasing number of overweight and obese children, the highest attention should be paid to primary prevention, since comorbidities such as adult-onset diabetes, high blood pressure, etc. can also occur in children and adolescents. Kindergartens provide good conditions for strengthening the personal health resources of children. After all, they are the first educational institutions that many children and parents from all social classes attend. Interdisciplinary cooperation between parents, pedagogues, doctors, therapists, health authorities, health insurance companies, associations and other municipal institutions should be pursued [33].

The literature research showed that there are a large number of intervention projects. The social and political interest in them is growing. The number of such projects to promote physical activity is likely to increase in the future. All intervention studies were able to demonstrate the effectiveness of physical activity promotion in kindergarten on the motor development of the child. Several authors also confirm a positive influence on the emotional and psycho-social development of the child [34]. The promotion of physical activity in kindergarten has, however, been on the minds of experts for some time. The increase in postural and motor deficits in children and adolescents and the associated cognitive consequences have led to various studies and publications in recent years. In all studies, effective movement education in the elementary school is repeatedly mentioned as the 
foundation for the holistic development of children. However, the implementation of this effective physical education often proves to be a difficult undertaking, even though the health-promoting effect of sport and exercise is well anchored in people's consciousness [35].

\section{REFERENCES}

1. Lohaus, A., \& Glueer, M. (2014). Entwicklungsfoerderung im Kindesalter. Grundlagen, Diagnostik und Interventionen. Goettingen: Hogrefe.

2. Beelmann, A., Pfost, M., \& Schmitt, C. (2014). Praevention und Gesundheitsfoerderung bei Kindern und Jugendlichen. Zeitschrift für Gesundheitspsychologie, 22(1):114.

3. Pauen, S. (2007). Was Babys denken. Eine Geschichte der ersten Lebensjahre. Muenchen: Reinhardt.

4. Fischer, K. (2011). Konzept und Wirksamkeit der Psychomotorik in der Frühförderung. Fruehfoerderung Interdisziplinaer, 30:2-16.

5. Ecarius, J., Koebel, N., \& Wahl, K. (2011). Familie, Erziehung und Sozialisation. Wiesbaden: VS für Sozialwissenschaften.

6. Lampert, C., \& Schwinge, C. (2013). Zum elterlichen Umgang mit Medien. Ein Ueberblick ueber den Stand der Forschung. In U. Wagner, C. Gebel \& C. Lampert (Hrsg.), zwischen Anspruch und Alltagsbewaeltigung: Medienerziehung in der Familie (19-52). Berlin: VISTAS.

7. Six, U., \& Gimmler, R. (2010). Medienerziehung in der Familie. Ein Ratgeber für Eltern. Berlin: VISTAS.

8. Zimmer, R. (2011). Handbuch der Psychomotorik. Freiburg: Herder.

9. Rethorst, S., Fleig, P., \& Willimczik, K. (2009). Effekte motorischer Foerderung im Kindergartenalter. In W. Schmidt (Hrsg.), Zweiter Deutscher Kinder- und Jugendsportbericht (2., ueberarbeitete Aufl.), (237-254). Schorndorf: Hofmann.

10. Roehr-Sendlmeier, U. (2009): Entwicklungsfoerderung durch Bewegung: eine lebenslange Perspektive. Motorik, 32(2):43-58.

11. Zimmer, R. (2012). Handbuch der Bewegungserziehung. Freiburg: Herder.

12. Zimmer, R. (2011). Bewegung - Motor der kindlichen Entwicklung. In: Keller, H. (Hrsg.), Handbuch der Kindheitsforschung (4. Aufl., 1112-1128). Bern: Hans Huber.

13. Zimmer, R. (2013). Bildung durch Bewegung Motorische Entwicklungsfoerderung. In $\mathrm{M}$. Stamm \& D. Edelmann (Hrsg.), Handbuch fruehkindliche Bildungsforschung (587-601). Wiesbaden: Springer.

14. Bamler, V., Werner, J., \& Wustmann, C. (2010). Lehrbuch Kindheitsforschung. Grundlagen,
Zugänge und Methoden. Weinheim, München: Juventa.

15. Schack, T., \& Pollmann, D. (2014). Motorik. In A. Lohaus \& M. Glueer (Hrsg.), Entwicklungsfoerderung im Kindesalter. Grundlagen, Diagnostik und Intervention (4562). Goettingen: Hogrefe.

16. Anderson, J. R. (2001). Kognitive Psychologie. Heidelberg: Spektrum.

17. Burger, K. (2010). How does early childhood care and education affect cognitive development? An international review of the effects of early interventions for children from different social backgrounds. Early childhood research quarterly, 25(2):140-165.

18. Kastner, J., Lipsius, M., Hecking, M., Petermann, F., Petermann, U., Mayer, H., \& Springer, S. (2011). Kognitive Leistungsprofile motorisch- und sprachentwicklungsverzoegerter Vorschulkinder. Kindheit und Entwicklung, 20(3):173-185.

19. Lenzing, B., \& Lenzing, R. (2007). Lernfeld Grundschule. In: H. Jürgen Beins (Hrsg.). Kinder lernen in Bewegung. Dortmund: Borgmann Media.

20. Zarotis, G. (2019). Positive self-concept through physical-sport activity of preschool children. American Journal of Humanities and Social Sciences Research, 3(2):53-60.

21. Asendorpf, J. B. (2012). Persoenlichkeitspsychologie. Berlin, Heidelberg: Springer- Verlag.

22. Fröhlich-Gildhoff, K. (2013). Angewandte Entwicklungspsychologie der Kindheit. Stuttgart: Kohlhammer.

23. Zarotis G. (2018). Psychosocial Prevention of Dangerous Behaviour in Childhood and Adolescence. American Journal of Humanities and Social Sciences Research, 2(11):66-72.

24. Hellmich, F. (2011). Selbstkonzepte im Grundschulalter. Stuttgart: Kohlhammer.

25. Bischof-Koehler, D. (2011). Soziale Entwicklung in Kindheit und Jugend: Bindung, Empathie, Theory of Mind. Stuttgart: Kohlhammer.

26. Viernickel, S. (2013). Soziale Entwicklung. In Stamm, M., \& Edelmann, D. (Hrsg.), Handbuch fruehkindliche Bildungsforschung (633-652). Wiesbaden: Springer.

27. Frank, A. (2008). Kinder in ihrer sozialemotionalen Entwicklung fördern (3. Aufl.). Freiburg: Herder.

28. Franiek, S., \& Reichle, B. (2007). Elterliches Erziehungsverhalten und Sozialverhalten im Grundschulalter. Kindheit und Entwicklung, 16(4), 240-249.

29. Petermann, F., \& Wiedebusch, S. (2008). Emotionale Kompetenz bei Kindern (2., ueberarb. Aufl.). Goettingen: Hogrefe. 
30. Schneewind, K. A. (2008). Sozialisation und Erziehung im Kontext der Familie. In R. Oerter \& L. Montada (Hrsg.), Entwicklungspsychologie (117-145). Weinheim, Basel: Beltz.

31. Ludwig, G., Pahl, A. K., \& Poehlmann, R. (2011). Sensomotorik - Psychomotorik Soziomotorik für heilpaedagogischmedizinische Berufe. Köln: Verlag EINS.

32. Eggert, T., Reichenbach, C., \& Bode, S. (2003). Das Selbstkonzeptinventar (SKI) für Kinder im Vorschul- und Grundschulalter. Theorie und Moeglichkeiten der Diagnostik. Dortmund: Borgmann.
33. Weiß, A., Weiss, W., Stehle, J., Zimmer, K., Heck, H., \& Raab, P. (2004). Beeinflussung der Haltung und Motorik durch Bewegungsfoerderprogramme bei Kindergartenkindern. In: Deutsche Zeitschrift für Sportmedizin, 55, 101-105.

34. Zimmermann, P. (2006). Grundwissen Sozialisation. Einfuehrung zur Sozialisation im Kindes- und Jugendalter. Wiesbaden: VS.

35. Krombholz, H. (2005). Bewegungsfoerderung im Kindergarten - ein Modellversuch. Schorndorf: Hofmann. 